\title{
PERANCANGAN DESAIN INTERIOR PERPUSTAKAAN RAMAH ANAK SEBAGAI UPAYA MENUMBUHKAN MINAT BACA ANAK DI MASJID AL ANIAH BANDUNG
}

\author{
Djoko Murdowo ${ }^{1}$, Widyanesti Liritantri ${ }^{2}$, Yustriyani Syifa $^{3}$, Rifa Munadia $^{4}$ \\ ${ }^{1,2,3,4}$ Desain Interior, Fakultas Industri Kreatif, Universitas Telkom \\ Jl. Telekomunikasi, Terusan Buah Batu, Bandung, 40257 \\ djoko@telkomuniversity.ac.id ${ }^{1}$, widyanestit@elkomuniversity.ac.id ${ }^{2}$, \\ syifaauliya82@gmail.com ${ }^{3}$, $\underline{\text { munadiarifa@gmail.com }}^{4}$
}

\begin{abstract}
ABSTRAK
Minat baca masyarakat Indonesia masih sangat rendah, terutama pada anak-anak. Banyak faktor yang mempengaruhi minimnya minat baca, salah satunya adalah kurangnya fasilitas yang menyediakan tempat bacaan untuk anak-anak. Demikian juga yang terjadi di Masjid Al-Aniah, yang berada dalam suatu komplek Cluster Perumahan dengan jumlah jiwa hampir 1800 jiwa, yang mempunyai ruang baca yang tidak tertata dengan baik, tidak nyaman, rak penyimpanan yang tidak teratur serta belum mencerminkan desain karakter anak baik pada warna, ergonomic, layout dll. Urgensi penelitian ini adalah bagaimana desain interior perpustakaan atau ruang baca dapat mendorong dan memotivasi anak gemar dan senang membaca. Penelitian ini bertujuan merancang ruang baca anak sebagai alternative untuk mingkatkan minat baca, dapat diwujudkan dengan menciptakan perancangan ruang yang sesuai dengan kebutuhan karakteristik pada anak..Metode pengabdian masyarakat dilakukan dengan metode kaualitatif dengan studi kasus di Masjid Al Aniah Bandung, yang dilakukan dengan wawancara, observasi langsung dan diskusi dengan ketua DKM dan Marbot. Hasil dari penelitian ini rancangan ruang baca di lantai 2 dengan menerapkan lay out, sirkulasi zoning blocking area yang dapat memberikan rasa aman dan anyaman pada anak anak. Ruang bacaan dirancang dengan menerapkan usur-unsur desain yang sesuai dengan karakteristik anak, seperti, unsur warna, unsur bentuk dan furniture yang dapat mendukung aktifitas anak seperti belajar, membaca buku, bermain permainan edukatif, dan melakukan kegiatan seni.
\end{abstract}

Kata kunci: Perancangan, Perpustakaan, desain interior, ramah anak, masjid

\begin{abstract}
The reading interest of the Indonesian people is still very low, especially among children. Many factors affect the lack of interest in reading, one of which is the lack of facilities that provide reading space for children. Likewise, what happened at the Al-Aniah Mosque, which is in a housing cluster complex with a population of nearly 1,800 people, which has a reading room that is not well organized, uncomfortable, storage shelves that are irregular and do not reflect the character design of the children either. color, ergonomic, layout etc. The urgency of this research is how the interior design of a library or reading room can encourage and motivate children to love and enjoy reading. This study aims to design a children's reading room as an alternative to increase reading interest, it can be realized by creating a space design that suits the needs of the characteristics of the child. Community service methods are carried out by qualitative methods with case studies at Masjid Al Aniah Bandung, which are conducted by interview, direct observation and discussion with the head of DKM and Marbot. The results of this study are the reading room design on the second floor by implementing a layout, zoning blocking area circulation that can provide a sense of security and webbing for children. The reading room is designed by applying design elements that are in accordance with children's characteristics, such as color elements, shape elements and furniture that can support children's activities such as learning, reading books, playing educational games, and doing art activities.
\end{abstract}

Keywords: Design, Library, interior design, child friendly, mosque 


\section{PENDAHULUAN}

Kebiasaan membaca dapat dimulai dengan menumbuhkan minat baca di masyarakat dan melalui proses pembiasaan yang dilakukan sejak dini (Primadesi, 2018). Namun sayangnya minat baca masyarakat Indonesia masih sangat rendah, terutama pada anak-anak. Banyak faktor yang mempengaruhi minimnya minat baca, salah satunya adalah kurangnya fasilitas yang menyediakan tempat bacaan untuk anak-anak Untuk menunjang minat baca pada anak- anak tentunya dengan menyediakan area baca dengan desain interior yang yang memiliki dampak positif pada perkembangan dan sosial anak (Stewart, 2016). Membangun perpustakaan atau area baca ramah anak harus memahami sifat anak-anak yang aktif, kreatif, energik, berimajinasi, suka bermain, serta memiliki rasa ingin tahu yang besar. Disamping itu Ruang bacaan harus memiliki fungsi utama sebagai fungsi informasi, edukasi dan rekreasi. Masjid merupakan sebuah tempat yang selain sebagai tempat ibadah, juga dapat dikembangkan sebagai pusat edukasi dengan menyediakan ruang baca bagi anak anak, sebagai upaya meningkatkan minat baca, pembentukan karakter dan mendekatkan anak pada masjid.

Demikian juga yang terjadi di Masjid Al-Aniah, yang berada dalam suatu komplek Cluster Perumahan dengan jumlah Kepala Keluarga hampir 385 KK dengab jumlah jiwa hampir 1800 jiwa. Lokasi dan area Masjid Al Aniah cukup luas dengan halaman depan yang masih memungkinkan sebagai ruang publik utamanya anak-anak untuk bersosialisasi dan berinteraksi dengan masjid. Salah satu tempat edukasi yang diharapkan adalah perpustakaan atau ruang baca anak yang representatif. Namun sayang ruang baca yang ada di Masjid Al Aniah tidak tertata dengan baik, tidak nyaman, rak penyimpanan yang tidak teratur serta belum mencerminkan desain karakter anak baik pada warna, ergonomic, layout dll.

Urgensi penelitian ini adalah bagaimana memberikan alternatif ruang baca selain perpustakaan, dimana perpustakaan dikononotasikan formal, untuk orang dewasa dan kurang dapat mewadahi aktivitas anak. Perancangan fasilitas ruang baca, rasionalitasnya akan dapat mendorong dan memotivasi anak melalui bentuk desain interior perpustakaan atau ruang baca yang memberikan rasa nyaman pada anak (Room to Read, 2015)

Tujuan kegitan ini adalah membangun ruang baca anak sebagai alternative untuk mingkatkan minat baca, dapat diwujudkan dengan menciptakan perancangan ruang yang sesuai dengan kebutuhan karakteristik pada anak. Dalam ruang bacaan perlu diadakan area bermain edukatif bagi anak untuk melatih kreativitas imajinasi anak serta membuat anak 
senang dan tidak merasa bosan berada di dalam perpustakaan sehingga mereka dapat belajar dan bermain.

Solusi pemecahan dari permasalahan pengabdian masyarakat ini adalah membangun ruang baca atau perrpustakan masjid yang diharapkan dapat menarik anak untuk melakukan kegiatan membaca. Satu salah satu aspek terpenting untuk mendesain perpustakaan atau ruang baca adalah dengan mempertimbangkan lingkungan interior fisik yang terdiri dari perencanaan ruang interior, dan suasana interior seperti pemilihan penerangan, furnitur, bahan dan finishing (Sufar, 2012).

Ruang bacaan dirancang dengan menerapkan usur-unsur desain yang sesuai dengan karakteristik anak, seperti lay out, suasana, unsur warna, unsur bentuk dan furniture yang dapat mendukung aktifitas anak seperti belajar, membaca buku, bermain permainan edukatif, dan melakukan kegiatan seni. Beberapa penelitian menyebutkan pentingnya desain interior di perpustakaan, diantaranya untuk menarik minat kunjung pemustaka (Puspita \& Jumino, 2014), meningkatkan minat baca, membentuk citra positif perpustakaan (Adjie, M.D., 2011), dan kepuasan pemustaka (Aryanti dkk, 2015).

\section{METODE}

Metode pengabdian masyarakat dilakukan dengan metode kaualitatif dengan studi kasus di Masjid Al Aniah Bandung. Kegiatan pengabdian dilaksanakan pada bulan Juni 2020-Agustus 2020. Tahapan kegiatan dilakukan sebagai berikut:

a. Tahap persiapan dan survei yang berupa kunjungan lokasi di Masjid Al Aniah Bandung untuk melihat keadaan dan observasi keadaan ruang dan mebel pendukung. Pada tahapan ini dilakukan pula diskusi dengan Ketua DKM dan marbot, untuk mengetahui secara rinci bentukan kontribusi yang paling sesuai untuk Masjid ini,

b. Tahap kedua berupa proses desain sebagai pengembangan konsep solusi yang ditawarkan pada permasalahan di Masjid Al-Aniah. Proses perancangan didahului dengan studi referensi model kebutuhan pendidikan anak, ruang yang comfortable dan furniturfurnitur yang bersifat multifungsi dan dapat dialihfungsikan dengan mudah (convertible) dan mudah dipindahkan (Movable) karena model mebel ini dinilai paling sesuai dengan kebutuhan di ruang masjid yang secara penempatan sangat terbatas luasannya. Pada tahap ini, furnitur ortogonal, potongan furnitur, detail furnitur meja kerja, dan bentuk 
perspektif diproduksi. Setelah tahap desain selesai dilakukan proses selanjutnya adalah rendering untuk menampilkan gambar perspektif pada lembar kerja.

c. Tahap ketiga adalah Produksi yang akan menghasilkan sebuah ajuan gambar kerja yang dapat direalisasikan untuk diwujudkan menjadi sebuah produk jadi yang sesungguhnya. Proses desain diproduksi dan dikerjakan oleh tenaga ahli berpengalaman dan mahasiswa Studi Desain Interior dari Telkom University.

\section{HASIL DAN PEMBAHASAN}

\section{Layout, Sirkulasi, Zoning \& Blocking}

Dalam perancangan, data-data baik fisik dan non-fisik akan disesuaikan dengan kondisi eksisting bangunan dan akan diterapkan sesuai kebutuhan akan perancangan dan optimalisasi fungsi ruang sesuai dengan data yang telah dikumpulkan, kemudian disusun dan dianalisis, disesuaikan dengan data lapangan yang ada dalam objek perancangan dengan standarisasi yang baik dalam sebuah perancangan interior.

Layout ruangan yang dipakai adalah di lantai 2 untuk memberikan rasa nyaman, dan suasana tenang, disamping itu memberikan anak untuk berekspresi, karena lay out ruang yang dibuat luas dan sirkulasi yang baik. Zoning dan blocking diatur dengan melakukan pemisahan ruang area private, umum dan service, dalam hal ini ruang baca ditempatkan pada ruang private namun lebih ke penggunaan umum utamanya anak anak.
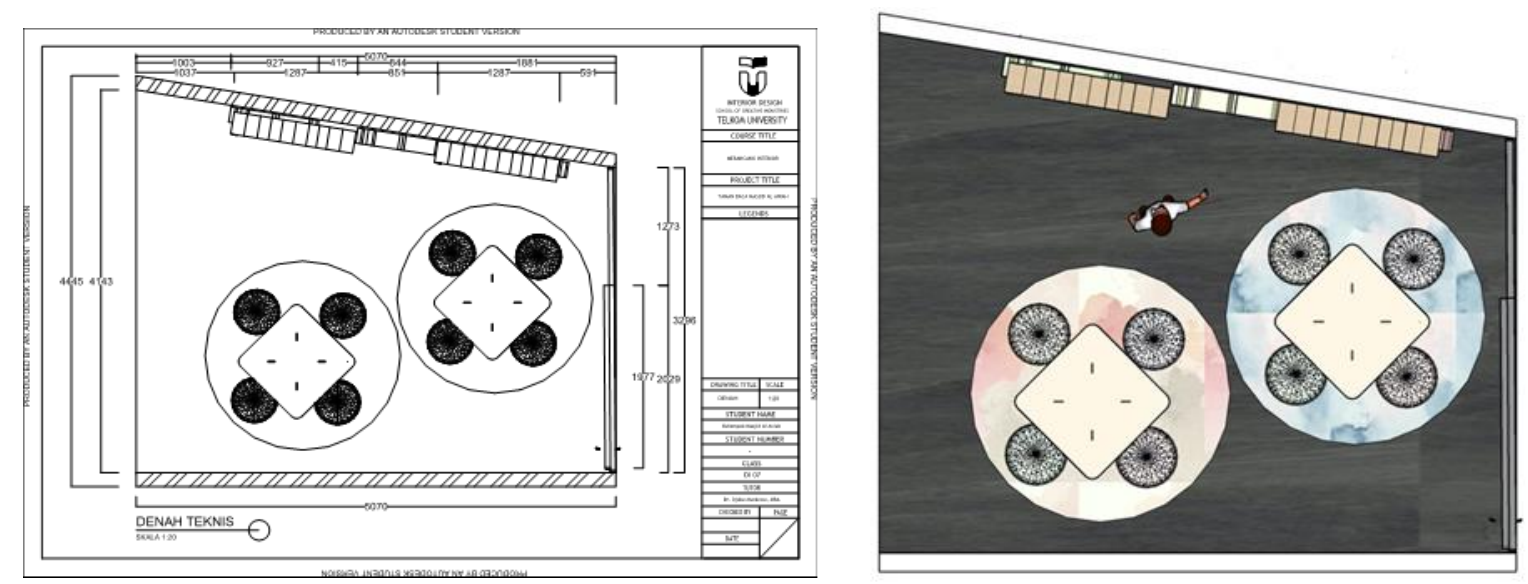

\section{Gambar 1. Denah Furnitur Perpustakaan}

Taman baca akan didesain dengan 2 area, yaitu area rak dan area meja untuk membaca. Pembagian ruang didasarkan pada kebutuhan dan aktivitas yang terjadi di taman baca pada saat beroperasional. Terlihat dari gambar di atas, lantai pada taman baca menggunakan parket 
kayu berwarna abu-abu tua dengan tujuan memberikan kesan nyaman, dan bersih. Pada area membaca terdapat sepasang 4 kursi yang dilengkapi dengan meja dan karpet.

\section{Konsep Bentuk, Warna, Material}

\section{a. Konsep Bentuk}

Konsep bentuk yang dapat adalah bentuk-bentuk geometris dasar. Konsep bentuk geometris dapat dapat dilihat pada penggunaan kursi dan meja di area membaca. Selain menggunakan bentuk geometris, bentuk non geometris juga diaplikasikan pada penggunaan furnitur rak buku dan ceiling. Bentuk non geometris diaplikasikan dengan tujuan membuat ruang lebih menarik.
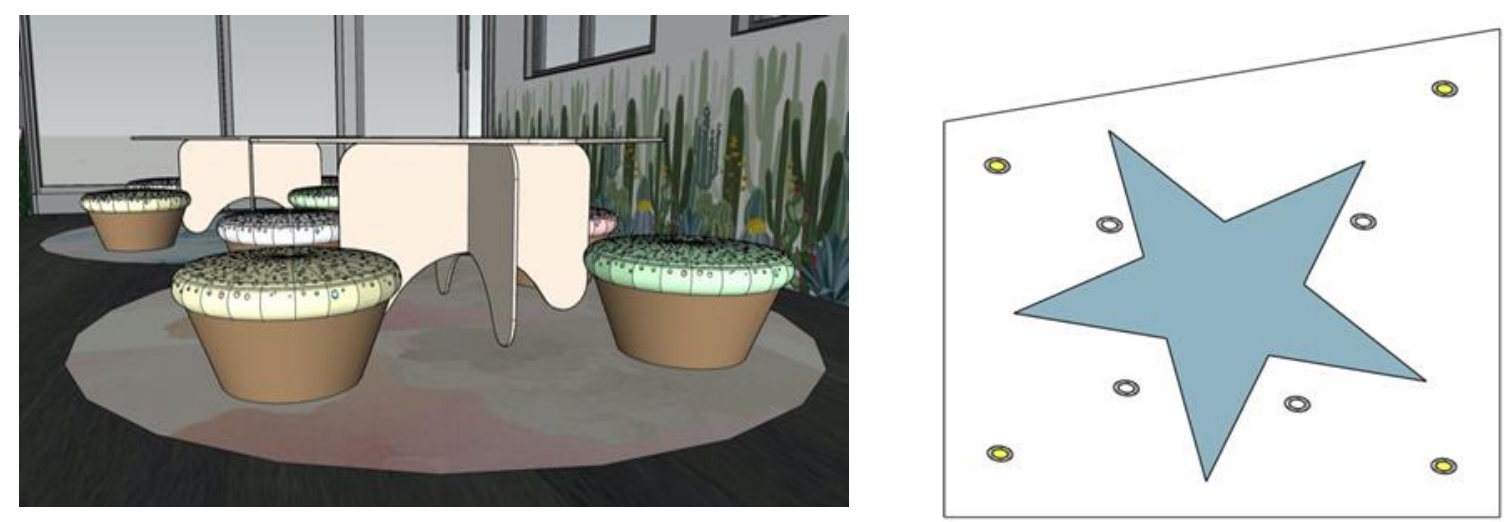

Gambar 2. Konsep Bentuk Perpustakaan

\section{b. Konsep Warna}

Untuk pemilihan warna-warna dapat menggunakan warna merah muda, biru, kuning, hijau, dan warna kontras lainnya. Dalam perancangan ini mendesain ruangan menjadi tampak berwarna dan mampu menciptakan rasa senang bagi anak (Shofaussamawati, 2014). Dalam abdimas ini, warna kuning memberikan kesan ceria dan dapat memotivasi anak. Serta, digunakan warna lain yaitu hijau dan merah muda sebagai perpaduan untuk memberikan efek sejuk, nyaman dan dapat meningkatkan minat baca anak. Warna juga dapat memainkan peran positif mempengaruhi peserta didik dan retensi kognitif (Dzulkifli \& Mustafar, 2013).
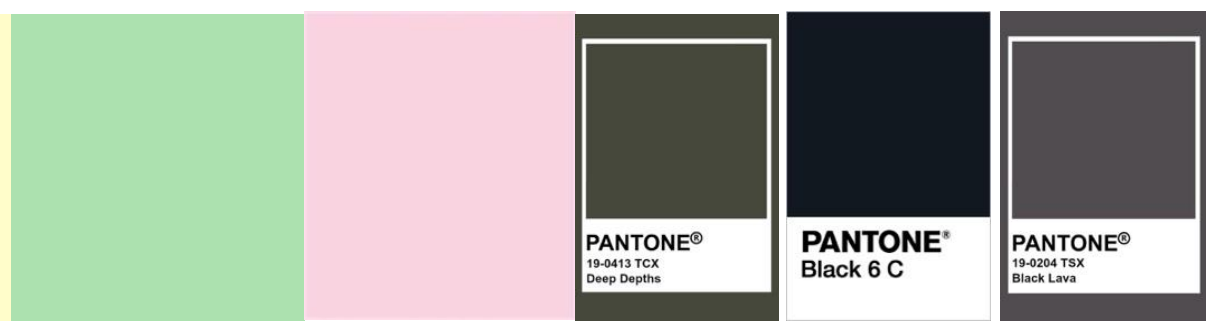

Gambar 3. Konsep Warna Perpustakaan 


\section{c. Konsep Material}

Pemilihan penggunaan furniture dan aksesoris interior perlu diperhatikan agar sesuai dengan aktifitas anak. Merancang konsep furniture yang memperhatikan material dan bentuknya, seperti memilih menggunakan furniture yang tidak memiliki ujung permukaan tajam karena menyesuaikan dengan sifat anak yang aktif. Pemilihan furniture juga dapat menggunakan bentukan bentukan furniture yang unik dan imajinatif. Untuk material furniture dapat menggunakan kayu/HPL. Material finishing yang digunakan adalah material yang ramah lingkungan, aman bagi anak dan tidak mengandung racun. Material utama yang digunakan adalah material kayu. Finishing yang digunakan untuk elemen interior dapat menggunakan wallpaper dengan gambar pemandangan alam atau gambar imajinatif lainnya yang menciptakan suasana ceria.
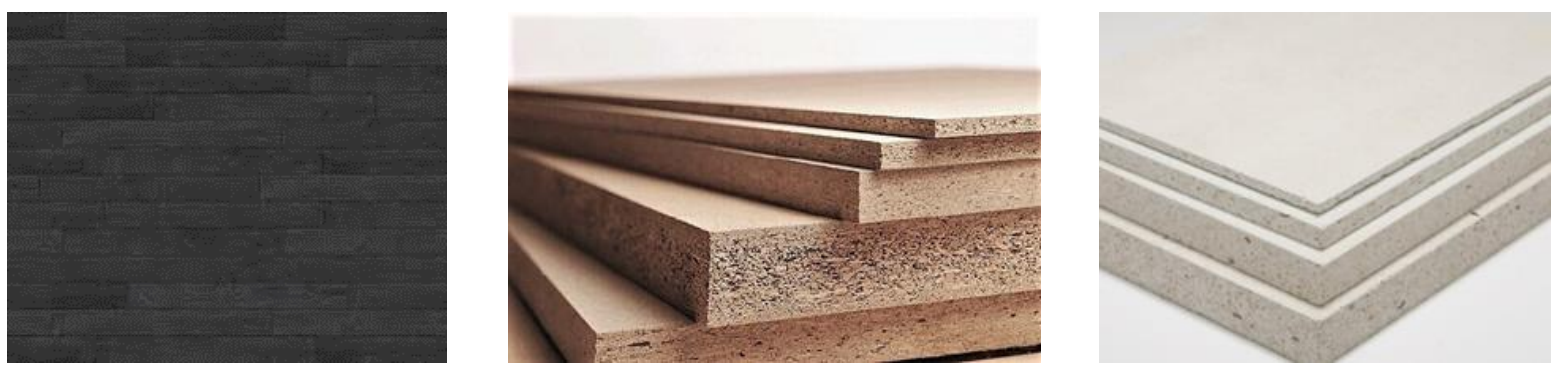

Gambar 4 : Pemilihan Material yang akan digunakan

Terlihat dari gambar di atas, lantai pada taman baca menggunakan parket kayu berwarna abuabu tua dengan tujuan memberikan kesan nyaman, dan bersih. Material dinding menggunakan cat berwarna putih dan wallpaper yang bertemakan 'hutan' agar lebih menarik dan membuat anak berimajinasi. Material ceiling menggunakan gypsum board berwarna putih.
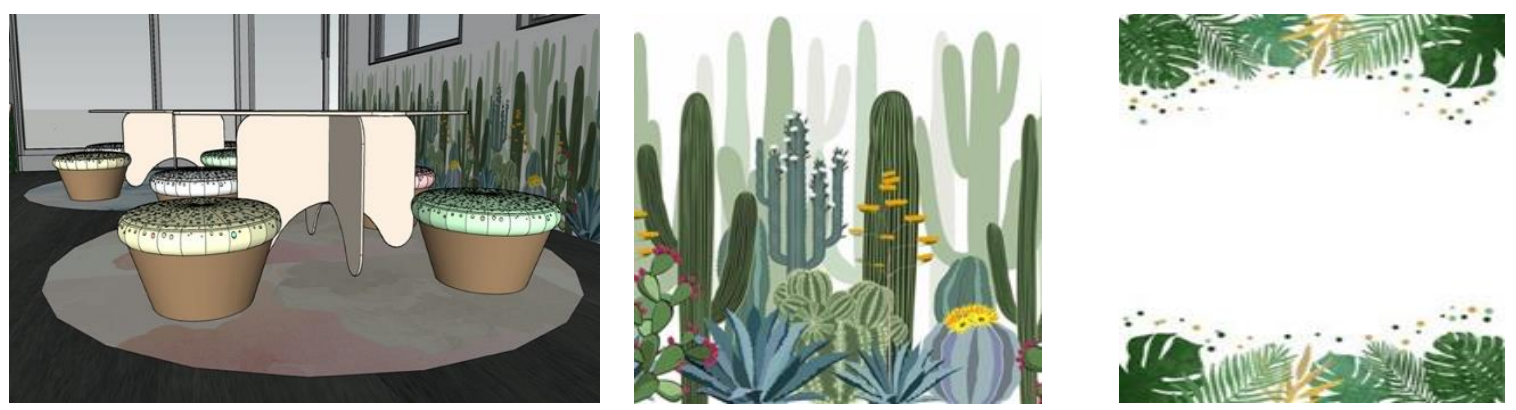

Gambar 5. Konsep Material Perpustakaan 


\section{d. Penempatan Furnitur}

Konsep furniture mengacu pada konsep bentuk, yaitu konsep bentuk geometris dasar dan non geometris. Konsep bentuk geometris dapat dapat dilihat pada penggunaan kursi dan meja di area membaca. Selain menggunakan bentuk geometris, bentuk non geometris juga diaplikasikan pada penggunaan furnitur rak buku dan ceiling. Bentuk non geometris diaplikasikan dengan tujuan membuat ruang lebih menarik.
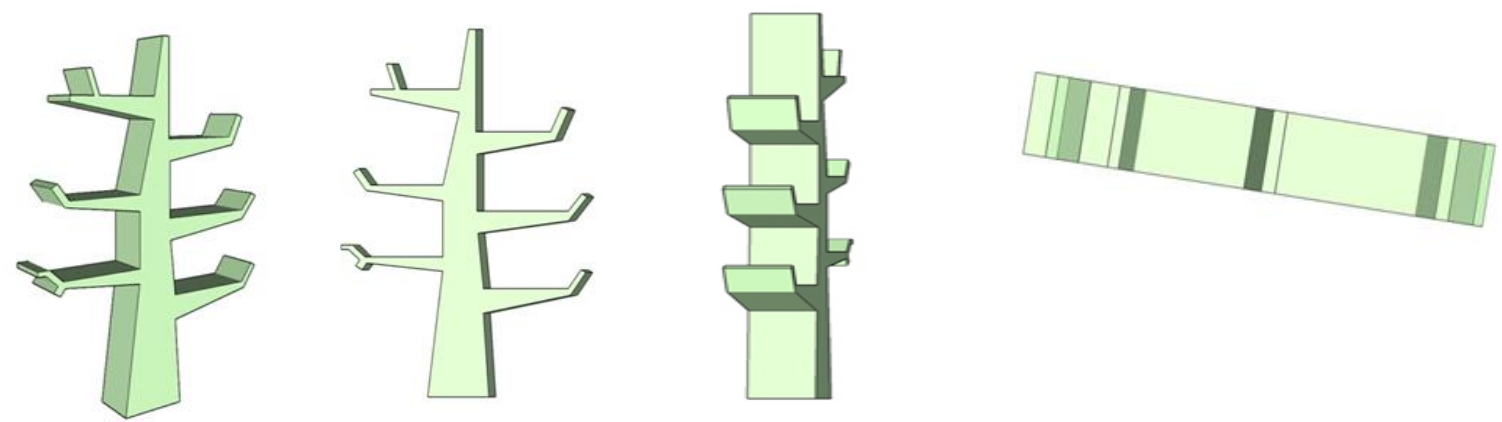

\section{Gambar 6. Rak Buku Perpustakaan}

Diaplikasikan supaya penyimpanan buku terlihat rapi dan menghemat tempat dengan menggunakan rak buku pada dinding dengan desain yang mudah dijangkau anak. Antropometri anak harus menghasilkan desain yang sesuai dengan postur dan dimensi tubuh sehingga harus ada pertimbangan ergonomic terkait kegiatan yang terjadi di ruan baca anak. Rak, meja dan kursi baca harus mendukung kegiatan sehingga siswa nyaman dan aman berkegiatan.

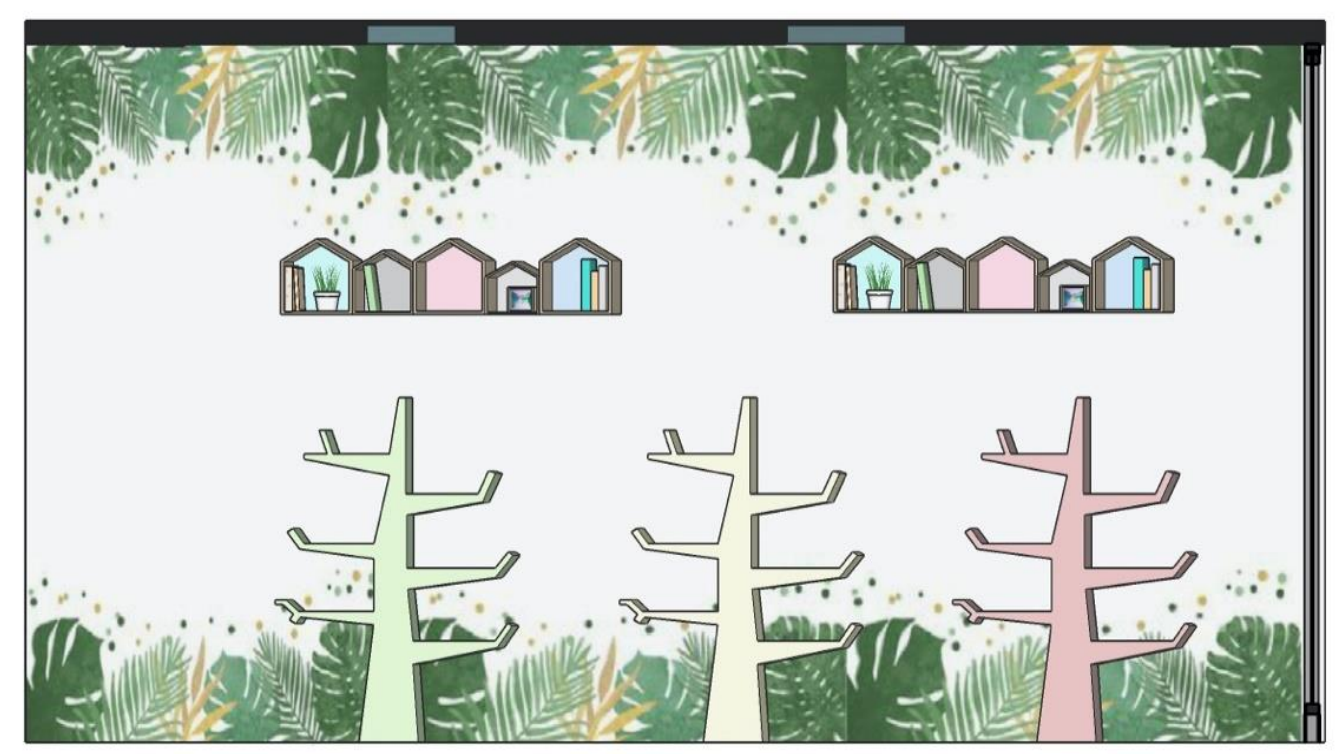

Gambar 7. Pengaplikasan Rak Buku Pada Dinding 


\section{e. Hasil Visualisa Ruang dan Suasana}

Menurut (Levy \& Weitz, 2001), atmosfer adalah mendesain suatu lingkungan melalui komunikasi visual, pencahayaan, warna, musik, dan penciuman untuk merangsang persepsi dan emosi dari pelanggan dan pada akhirnya untuk memengaruhi perilaku mereka. Suasana atau atmosfer merupakan suatu hal penting yang dapat membantu proses peningkatan kegemaran baca anak dan memberikan semangat agar minat baca pada anak dapat dicapai. Suasana yang dibutuhkan oleh anak anak pada ruang baca yang ramah adalah suasana yang tidak membosankan dengan memberikan warna, dekorasi dan informasi yang mudah diserap oleh anak anak ketika berada pada ruangan tersebut. Permainan warna dapat membantu daya tarik anak sehingga menciptakan ruang baca yang ramah. Menciptakan interior kaya warna, serta menyediakan area baca yang luas dengan menata ulang perabot akan membuat suasana nyaman.

Taman baca ini menerapkan gaya kontemporer, Untuk membuat ruang baca anak terasa lebih menarik dan tidak membosankan, konsep interior penggayaan nya dibuat semenarik mungkin namun tetap sesuai ergonomi dan antropometri anak-anak. Konsep penggayaan pada taman baca masjid al-inaih ini mengaplikasikan konsep gaya kontemporer. Gaya interior kontemporer menampakan tampilan ruang yang rapi dan bersih. Sebuah gaya desain yang bisa dikatakan merepresentasikan masa kini. Untuk pemilihan warna-warna dapat menggunakan warna merah muda, biru, kuning, hijau, dan warna kontras lainnya. Dipadukan warna netral seperti putih dan warna pastel agar lebih menarik. Dalam abdimas ini, warna kuning memberikan kesan ceria dan dapat memotivasi anak. Serta, digunakan warna lain yaitu hijau dan merah muda sebagai perpaduan untuk memberikan efek sejuk, nyaman dan dapat meningkatkan minat baca anak. Material utama yang digunakan adalah material kayu. Finishing yang digunakan untuk elemen interior dapat menggunakan wallpaper dengan gambar pemandangan alam atau gambar imajinatif lainnya yang menciptakan suasana ceria. 

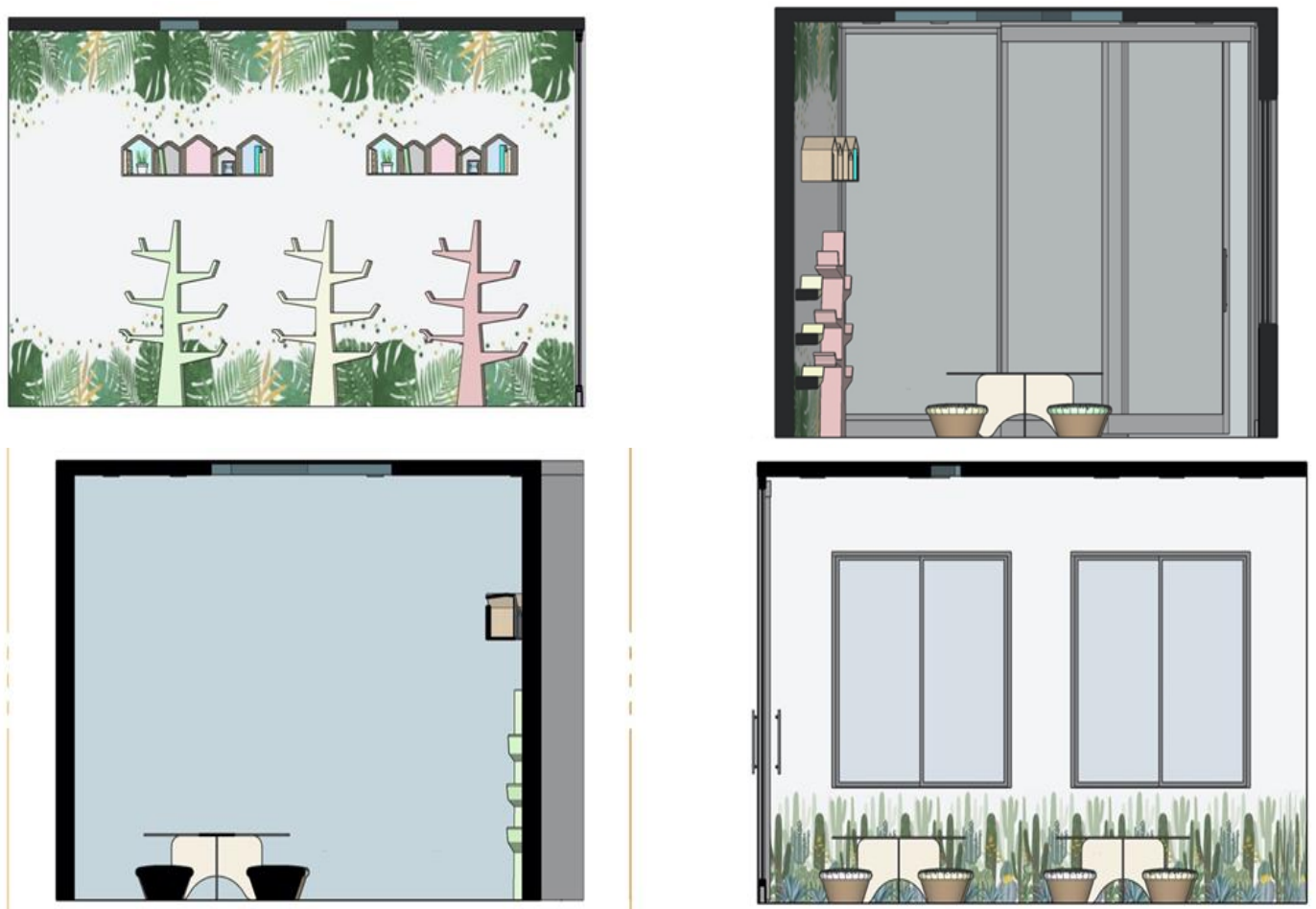

Gambar 8. Tampak Ruangaan

Secara garis besar dapat dikatakan bahwa konsep gaya kontemporer sangat cocok diaplikasikan di perancangan taman baca masjid al aniah. Taman baca ini mengusung tema dan konsep perancangan fun kontemporer sehingga anak-anak dapat lebih nyaman berada di dalamnya. Untuk menciptakan konsep desain ini, pemakaian wallpaper menjadi kunci agar ruangan terlihat menarik dan imajinatif.
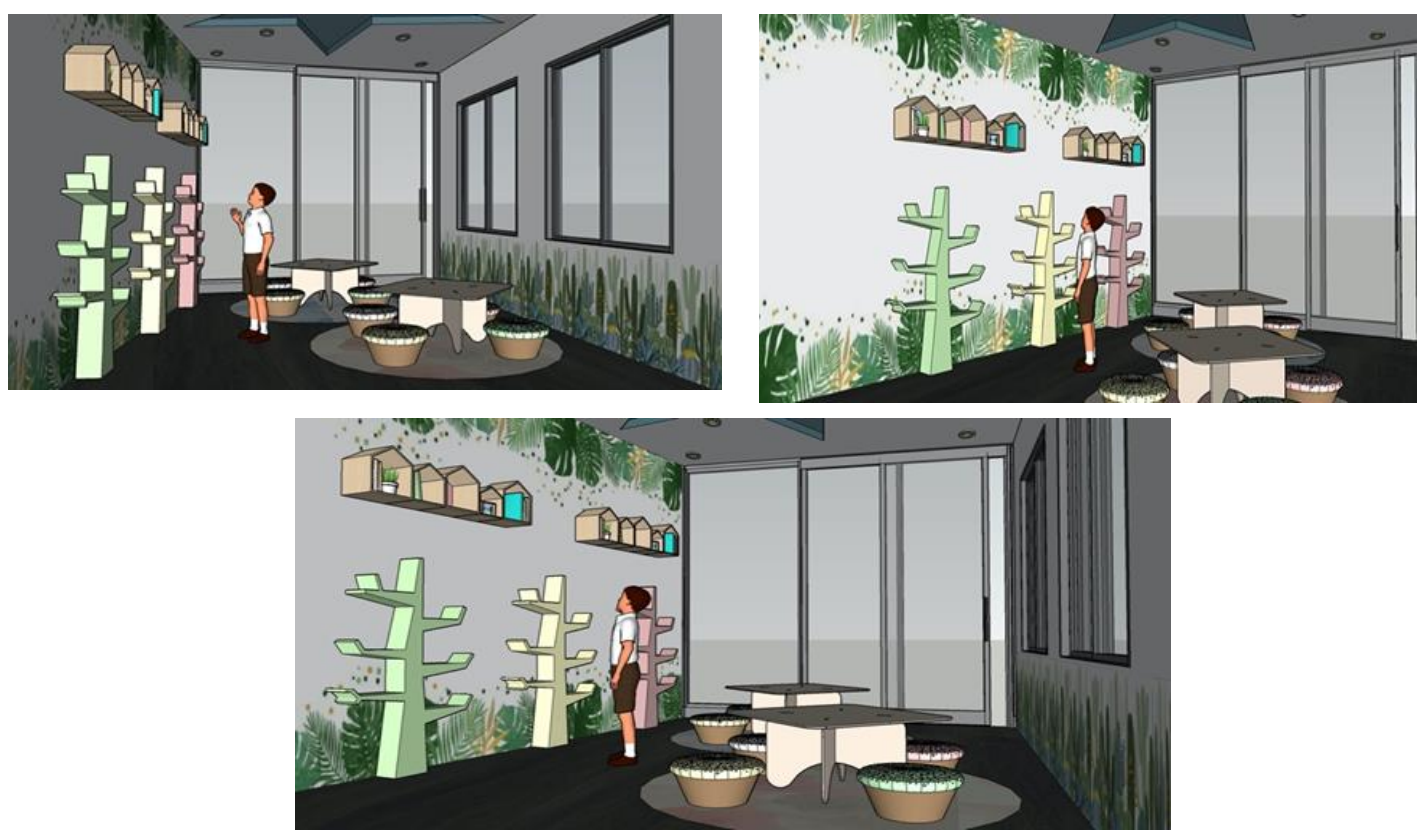

Gambar 9. Perspektif Ruangan 


\section{SIMPULAN}

Berdasarkan penjelasan di atas dapat diketahui jika pembangunan perpustakaan ramah anak sangat bagus diterapkan di area masjid, mengingat lingkungan masjid cukup luas dan terdapat kawasan bermain anak. Maka dapat disimpulkan

a. Merancang ruang baca anak dan perpustakaan di lantai 2 dengan meneapkan lay out, sirkulasi dn zoning blocking area yang dapat memberikan rasa aman dan anyaman pada anak anak

b. Ruang bacaan dirancang dengan menerapkan usur-unsur desain yang sesuai dengan karakteristik anak, seperti, unsur warna, unsur bentuk dan furniture yang dapat mendukung aktifitas anak seperti belajar, membaca buku, bermain permainan edukatif, dan melakukan kegiatan seni.

c. Penempatan furniture dan rak buku pada dinding dengan desain yang mudah dijangkau anak. Antropometri anak harus menghasilkan desain yang sesuai dengan postur dan dimensi tubuh dan pertimbangan ergonomic sehinggaanak nyaman dan aman berkegiatan.

d. Ruang bacaan dirancang untuk mendukung aktifitas anak seperti belajar, membaca buku, bermain permainan edukatif, dan melakukan kegiatan seni. Dengan adanya perpustakaan ramah anak diharapkan anak-anak dapat lebih sering berkunjung ke perpustakaan untuk membaca, belajar, dan bermain.

\section{UCAPAN TERIMA KASIH}

Kami sebagai peneliti dan penulis pada jurnal ini mengucapkan terima kasih kepada pihak Masjid Al Aniah dan pihak jurusan S1 Desain Interior, Telkom University atas dukungan pada penelitian ini untuk keikutsertaan dalam kegiatan ilmiah ini.

\section{DAFTAR PUSTAKA}

Adjie Miyarso Dwi,(2011) "Pengaruh Desain Interior perpustakaan terhadap pembentukan citra positif perpustakaa”, EduLib, Vol. 1, No.1 (2011): 77-86.

Ariyanti Novarikha, Stefanus Pani Rengu, dan Hermintatik (2015) :Peran Desain Interior terhadap Kepuasan Pemustaka", Jurnal Administrasi Publik (JAP), Vol. 3, No. 11 (2015): 1868-1873. 
Dzulkifli.M. \& Mustafar.M. (2013). The Influence of Colour on Memory Performance: A Review. The Malaysian Journal of Medical Sciences. 20(2),3. Retrieved from http://www.ncbi.nlm.nih.gov/pubmed/?term=MustafarMF

Nugroho, D. A., \& Haryati, S. (2019). Menciptakan Desain Interior Perpustakaan Ramah Anak di Sekolah Dasar Negeri Potrobangsan 1 Kota Magelang: Best Practice. Jurnal Pustakawan Indonesia, 17(1).

Primadesi, Yona (2018) Dongeng Panjang Literasi Indonesia. Padang: Kabarita.

Puspita Inggar Ajeng dan Jumino (2014), "Pengaruh Desain Interior Terhadap Minat Kunjung di UPT erpustakaan Dian Nuswantoro Semarang", Jurnal Ilmu Perpustakaan, Vol. 3, No. 2(2014): 91-100

Room To Read (2015) Scaling Positive Impact:Establishing Libraries and Publishing Children's Books with Partners in Indonesia. Jakarta: ProVisi Education

Rudi Sumadi, "Peranan Desain Interior Perpustakaan bagi Pemustaka di Perpustakaan P3DSPBKP," Jurnal Pari, Vol. 2, No. 1 (2016): 25-30.

Shofaussamawati (2014) Menumbuhkan Minat Baca dengan Pengenalan Perpustakaan pada $\begin{array}{llllll}\text { Anak Sejak } & \text { Dini. Jurnal Libraria } 2 & \text { (1): }\end{array}$ http://journal.stainkudus.ac.id/index.php/Libraria/article/view/1189

Stewart, P (2016) School library design, facilities and resources for sustainable cognitive and social development of students: An evaluative case study. International Association of School Librarianship. Selected Papers from the ...Annual Conference, 1-20. Retrieved from https://search.proquest.com/docview/1928619382?accountid=16943

Sufar.,S.,Talib.A,. Hambali, H., Towards a better Design: Physical Interior Environments of Public Libraries in Peninsular Malaysia, Procedia - Social and Behavioral Sciences 42( $2012) 131$ 